\title{
Constraints Analysis in Hybrid Paddy Farming in Eastern Zone of Uttar Pradesh using Garrett Ranking Technique
}

\author{
Sachchidanand Upadhyay ${ }^{1 *}$, V. K. Singh ${ }^{1}$, Arjun Prasad Verma ${ }^{2}$, \\ Ashwani Kumar Verma ${ }^{3}$ and Kumari Asha ${ }^{1}$ \\ ${ }^{I}$ Department of Agricultural Extension, CSAUAT, Kanpur, Uttar Pradesh, India \\ ${ }^{2}$ Agriculture Extension, KVK, Jhansi, Uttar Pradesh, India \\ ${ }^{3}$ Rama University, Kanpur, Uttar Pradesh, India \\ *Corresponding author
}

\section{A B S T R A C T}

\section{Keywords}

Constraints, Hybrid paddy farming, Garrett' ranking technique

\section{Article Info}

Accepted:

07 January 2021

Available Online:

10 February 2021
The present study was conducted in two purposively selected district of UP to identify the constraints perceived by farmers in hybrid paddy farming. From each district ten villages and 5 respondents were selected from each village. Thus, a total of 100 farmers who actively involved in hybrid paddy farming were randomly selected from twenty villages of Ambedkar Nagar and Sultanpur district of Uttar Pradesh. Garrett' ranking technique was adopted to analyze the constraints as perceived by the respondents in hybrid rice farming. The results revealed that major constraints perceived by hybrid rice growers were hybrid paddy once sown cannot sow it again ranked first with Garrett mean score of 72.90, followed by higher seed cost with Garrett mean score of 68.41. Distasteful cooking quality was ranked third with Garrett mean score of 68.06 followed by falling problem of large varieties, less head rice recovery, less pricing ability and lack of demand, problem of Ripening time of hybrid rice, cheap grain quality and lack of knowledge about seed treatment were the other major constraints as perceived by farmer with Garrett score of 54.91, 54.90, 49.68, 48.03, 40.5 and 38.76, respectively.

\section{Introduction}

Rice is the most important food crops of India in terms of area, production and consumption. In India rice is grown in an area of $43.95 \mathrm{~m}$ ha with the production and productivity levels of $106.29 \mathrm{mt}$ and $2416 \mathrm{~kg} / \mathrm{ha}$ respectively during 2013-14 (Hariprasad et al., 2014). It's also recognized that these countries have rice as their staple food. Rice is grown under four different ecologies, with irrigated ecology accounting for the largest area (431.94 million/hectare) and highest production (110.15 metric tons) and productivity (25.50 tons/hectare) closely followed by rainfed shallow low lands. Rainfed upland, which accounts for nearly one fourth of the rainfed low land area, records one seventh of production. Region wise, the predominantly rainfed eastern zone accounts for 29.5 million hectare which is the largest area under rice in the country with highest production of 51.6 
metric tons but with the lowest productivity of 1.62 tons/hectare. While the irrigated north and south zones together accounting for nearly 12 million hectare, produce 37.5 metric tons recording a distinct yield edge over eastern India. The distribution pattern of rice growing districts based on productivity range reveal that of 563 districts, 115 districts (20.4\%) contribute to 36.9 million tons production with an average yield of 3.15 tons/hectare. They are largely located in the high productive states of Punjab, Tamil Nadu, Haryana and Andhra Pradesh. Around 103 $(18.3 \%)$ districts falling in the range of 2 to 2.5 tons/hectare are in Kerala, Karnataka and Uttar Pradesh. Over 345 (61.3\%) districts with yield levels less than that of the national average are distributed largely in the rainfed eastern, central and western states viz., Arunachal Pradesh, Assam, Bihar, Sikkim, Uttar Pradesh and Uttarakhand (Nirmala, 2011). The main reason for the cultivation of hybrid rice is to obtain better yield followed by higher profitability, suitable for parboiling, better resistance to pests and diseases. The increase in rice yields due to hybrid rice has, in turn, improved food security for an estimated 60 million additional people per year (Singh et. al., 2018). The present study was conducted with an objective to analyse the constraints elicited from the hybrid rice growers in hybrid rice production in Ambedkar Nagar and Sultanpur district of Uttar Pradesh state in India. There may be several impediments on the way. An understanding of these constraints and prospects will go a long way in decision making.

\section{Materials and Methods}

The eastern zone of Uttar Pradesh was purposively selected because there was more area of hybrid paddy cultivation. Seventeen districts come in eastern zone of Uttar Pradesh. Out of them two districts namely
Ambedkar nagar and Sultanpur were selected keeping in view the highest productivity in the year 2017-18. From each district, 2 blocks and 10 villages were selected randomly. From each village, a sample of 5 hybrid rice growers was selected using multi stage random sampling method. Thus, a total of 100 respondents were selected randomly for the present study. A well-structured and pretested interview schedule was used to collect data from respondents. Ex post facto research design was used in this study. Appropriate statistical tools were used to analyse the data in order to draw conclusion.

\section{Henry garrett's ranking technique}

This technique was used to evaluate the constraints faced by the researchers. The orders of merit given by the respondents were converted in to rank by using the formula. To find out the most significant factor which influences the respondent, Garrett's ranking technique was used. As per this method, respondents have been asked to assign the rank for all factors and the outcomes of such ranking have been converted into score value with the help of the following formula:

Percent position $=\frac{100\left(\mathrm{R}_{\mathrm{ij}}-0.5\right)}{\mathrm{N}_{\mathrm{I}}}$

Where

$R_{i j}$ - Rank given for the ith variable by the $j$ th respondents

$\mathrm{N}_{\mathrm{j}}$ - Number of variable ranked by jth respondents

With the help of Garrett's Table, the percent position estimated was converted into scores. Then for each factor, the scores of each individual were added and then total value of scores and mean values of score was calculated. The factors having highest mean 
value was considered to be the most important factor. Similar analysis was done by Dhanavandan (2016).

\section{Results and Discussion}

\section{Socio-economic profile of the respondents}

The results revealed (Table 1) that less than half of the respondents belong to middle age category $(48.00 \%)$, less than one third of the respondents had primary education (31\%), majority of the respondents $(93 \%)$ had pucca house, majority of the respondents belong to other backward caste $(50.00 \%)$, majority of the respondents had nuclear family $(67.00 \%)$, less than half of the respondents $(40.00 \%)$ were engaged in farming regarding hybrid rice cultivation and one third of the respondents $(30.00 \%)$ belong to small land holding categories. About less than half of the respondents $(45.00 \%)$ had a monthly income between Rs. 5,001 to 10,000 and majority of the respondents had high experience $(53.00 \%)$ in farming i.e. more than 30 year experience. Similar finding was done by Nirmala and Suhasini (2013).

\section{Constraints perceived by respondents in cultivation of hybrid rice}

The results revealed (Table 2) that seed can't use again in sowing was the most important constraint as perceived by respondents and ranked first with Garrett Mean Score of 74.58 followed by higher seed costs ranked second with a garret mean score of 65.74 .

Distasteful cooking quality was ranked third with a garret mean score of 63.9. Other constraints were less head rice recovery, falling problem of large varieties, less pricing ability \& Lack of demand, problem in ripening time of hybrid rice, lack of knowledge about seed treatment, and Cheap grain quality were ranked fourth, fifth, sixth, seventh, eighth and ninth with garret mean score of 55.58, 54.92, 49.68, 48.70, 41.66 and 41.16 , respectively.

The results revealed that (Table 3) distasteful cooking quality was the most important constraint and ranked first with garret mean score of 72.22 followed by seed can't use again in sowing ranked second most important constraints with a garret mean score of 71.22. High seed cost, falling problem of large varieties, less head rice recovery, less pricing ability \& lack of demand, problem of ripening time of hybrid rice, cheap grain quality and lack of knowledge about seed treatment were third, fourth, fifth, sixth, seventh, eighth and ninth most important constraints as perceived by farmers in cultivation of hybrid rice with garret mean score of $71.08,54.90,54.22,49.68,47.36$, 39.84 and 35.86 , respectively.

Overall constraints as perceived by Respondents in both district in Hybrid rice farming

The results revealed that (Table 4) seed can't use again in sowing was the most severe constraints as perceived by respondents in hybrid rice farming and ranked first with garret mean score of 72.90 followed by higher seed costs with garret mean score of 68.41. From above results it is inferred that respondents are less interested because growers can't use seed again in sowing because farmers have to bear the cost of buying seeds again and again. There are some varieties of hybrid paddy that are good in food but their seeds are expensive. Hybrid paddy is more expensive than HYV paddy. Other major constraints as perceived by respondents in cultivation of hybrid rice technologies were distasteful cooking quality, falling problem of large varieties, less head rice recovery, less pricing ability \& lack of demand, problem in ripening time of hybrid 
rice, cheap grain quality and lack of knowledge about seed treatment and ranked third, fourth, fifth, sixth, seventh, eighth and ninth rank with garret mean score of 68.06 , 54.91, 54.90, 49.68, 48.03, 40.50 and 38.76, respectively. At the time of consumption respondents perceived that it is not good to eat, so grow only to sell. Besides this, the problem of large varieties falling in hybrid paddy is more. There are some varieties of hybrid paddy that are good in food but their seeds are expensive, harvesting is a problem due to hybrid ripening in canal areas. because until the water dries, you cannot harvest. Due to this, sometimes the crop is damaged.

Table.1 Distribution of hybrid rice grower on the basis of their socio-economic profile ( $\mathrm{n}=100)$

\begin{tabular}{|c|c|c|c|c|}
\hline Sl. No. & Variable & Category & Frequency & $\%$ \\
\hline \multirow[t]{3}{*}{1.} & \multirow[t]{3}{*}{ Age } & Young (18-34 yrs) & 14 & 14.00 \\
\hline & & Middle (35-59 yrs) & 48 & 48.00 \\
\hline & & Old $(>59$ yrs $)$ & 38 & 38.00 \\
\hline \multirow[t]{5}{*}{2.} & \multirow[t]{5}{*}{ Educational Status } & Can read and write only & 4 & 4.00 \\
\hline & & Primary school & 31 & 31.00 \\
\hline & & High school & 24 & 24.00 \\
\hline & & Intermediate & 8 & 8.00 \\
\hline & & Graduation \& above & 23 & 23.00 \\
\hline \multirow[t]{3}{*}{3.} & \multirow[t]{3}{*}{ Type of house } & Katcha & 97 & 97.00 \\
\hline & & Mixed & 3 & 3.00 \\
\hline & & Pucca & 45 & 45.00 \\
\hline \multirow[t]{3}{*}{4.} & \multirow[t]{3}{*}{ Caste association } & General caste & 31 & 31.00 \\
\hline & & Other Backward caste & 50 & 50.00 \\
\hline & & Scheduled caste & 19 & 19.00 \\
\hline \multirow[t]{2}{*}{5.} & \multirow[t]{2}{*}{ Family type } & Nuclear family & 67 & 67.00 \\
\hline & & Joint family & 33 & 33.00 \\
\hline \multirow[t]{5}{*}{6.} & \multirow[t]{5}{*}{ Family occupation } & Farming & 40 & 40.00 \\
\hline & & Farming + Service & 23 & 23.00 \\
\hline & & Farming + Business & 17 & 17.00 \\
\hline & & Farming + Labour & 19 & 19.00 \\
\hline & & Caste occupation & 1 & 1.00 \\
\hline \multirow[t]{4}{*}{7.} & \multirow{4}{*}{$\begin{array}{l}\text { Monthly income range } \\
\text { (in Rs) }\end{array}$} & Below 5,000 & 10 & 10.00 \\
\hline & & $5,001-10,000$ & 45 & 45.00 \\
\hline & & $10,001-20,000$ & 33 & 33.00 \\
\hline & & $>20,000$ & 17 & 17.00 \\
\hline \multirow[t]{5}{*}{8.} & \multirow[t]{5}{*}{ Land holding } & Marginal (<1 ha) & 37 & 37.00 \\
\hline & & Small (1-2 ha) & 30 & 30.00 \\
\hline & & Semi-medium (2-4 ha) & 19 & 19.00 \\
\hline & & Medium (4-10 ha) & 12 & 12.00 \\
\hline & & Large (>10 ha) & 2 & 2.00 \\
\hline \multirow[t]{4}{*}{9.} & \multirow{4}{*}{$\begin{array}{l}\text { Farming experiences } \\
\text { (yrs) }\end{array}$} & Very Low experience (Less than 10) & 7 & 7.00 \\
\hline & & Low experience ( 10 to 20$)$ & 17 & 7.00 \\
\hline & & Medium experience (20 to 30 ) & 22 & 22.00 \\
\hline & & High experience (More than 30) & 53 & 53.00 \\
\hline
\end{tabular}


Table.2 Garrett's ranking for the constraints perceived by respondents in cultivation of hybrid rice in Ambedkar nagar district of Uttar Pradesh $(n=50)$

\begin{tabular}{|c|l|c|c|c|}
\hline Sl. No. & \multicolumn{1}{|c|}{ Constraints } & Total Score & $\begin{array}{c}\text { Garrett } \\
\text { Mean Score }\end{array}$ & Rank \\
\hline 1. & Lack of knowledge about seed treatment & 2083 & 41.66 & $8^{\text {th }}$ \\
\hline 2. & Higher seed costs & 3287 & 65.74 & $2^{\text {nd }}$ \\
\hline 3. & Seed can't use again in sowing & 3729 & 74.58 & $1^{\text {st }}$ \\
\hline 4. & Distasteful cooking quality & 3195 & 63.9 & $3^{\text {rd }}$ \\
\hline 5. & Less head rice recovery & 2779 & 55.58 & $4^{\text {th }}$ \\
\hline 6. & Falling problem of large varieties & 2746 & 54.92 & $5^{\text {th }}$ \\
\hline 7. & Cheap grain quality & 2058 & 41.16 & $9^{\text {th }}$ \\
\hline 8. & Less pricing ability \& Lack of demand & 2484 & 49.68 & $6^{\text {th }}$ \\
\hline 9. & The problem in ripening time of hybrid rice & 2435 & 48.70 & $7^{\text {th }}$ \\
\hline
\end{tabular}

Table.3 Garrett's ranking for the constraints perceived by respondents in cultivation of hybrid rice in Sultanpur district of Uttar Pradesh $(n=50)$

\begin{tabular}{|c|l|c|c|c|}
\hline Sl. No. & \multicolumn{1}{|c|}{ Constraints } & Total Score & $\begin{array}{c}\text { Garrett } \\
\text { Mean Score }\end{array}$ & Rank \\
\hline 1. & Lack of knowledge about seed treatment & 1793 & 35.86 & $9^{\text {th }}$ \\
\hline 2. & Higher seed costs & 3554 & 71.08 & $3^{\text {rd }}$ \\
\hline 3. & Can't use again in sowing & 3561 & 71.22 & $2^{\text {nd }}$ \\
\hline $\mathbf{4 .}$ & Distasteful cooking quality & 3611 & 72.22 & $1^{\text {st }}$ \\
\hline $\mathbf{5 .}$ & Less head rice recovery & 2711 & 54.22 & $5^{\text {th }}$ \\
\hline 6. & Falling problem of large varieties & 2745 & 54.90 & $4^{\text {th }}$ \\
\hline 7. & Cheap grain quality & 1992 & 39.84 & $8^{\text {th }}$ \\
\hline 8. & Less pricing ability \& Lack of demand & 2484 & 49.68 & $6^{\text {th }}$ \\
\hline 9. & The problem of Ripening time of hybrid rice & 2368 & 47.36 & $7^{\text {th }}$ \\
\hline
\end{tabular}

Table.4 Garrett's ranking for the constraints perceived by the respondents in cultivation of hybrid rice in both district (Ambedkar nagar and Sultanpur district) of Uttar Pradesh $(\mathrm{n}=100)$

\begin{tabular}{|c|l|c|c|c|}
\hline Sl. No. & \multicolumn{1}{|c|}{ Constraints } & Total Score & $\begin{array}{c}\text { Average } \\
\text { Garret score }\end{array}$ & Rank \\
\hline 1. & Lack of knowledge about seed treatment & 3876 & 38.76 & $9^{\text {th }}$ \\
\hline 2. & Higher seed costs & 6841 & 68.41 & $2^{\text {nd }}$ \\
\hline 3. & Can't use again in sowing & 7290 & 72.90 & $1^{\text {st }}$ \\
\hline 4. & Distasteful cooking quality & 6806 & 68.06 & $3^{\text {rd }}$ \\
\hline 5. & Less head rice recovery & 5490 & 54.90 & $5^{\text {th }}$ \\
\hline 6. & Falling problem of large varieties & 5491 & 54.91 & $4^{\text {th }}$ \\
\hline 7. & Cheap grain quality & 4050 & 40.50 & $8^{\text {th }}$ \\
\hline 8. & Less pricing ability \& Lack of demand & 4968 & 49.68 & $6^{\text {th }}$ \\
\hline 9. & The problem of Ripening time of hybrid rice & 4803 & 48.03 & $7^{\text {th }}$ \\
\hline
\end{tabular}


Chengappa et al., (2003) reported that the availability of subsidy on seed and to a limited extent on fertilizers and provision of knowledge on the higher yield potential of hybrids acted as motivational factors for farmers to undertake the cultivation of hybrid rice in Karnataka State of India. Besides, the farmers were of the opinion that the hybrid rice adapts well to varying situations and have resistance to pests and disease attacks, prompting them to go for hybrid cultivation. Further, it was noted that a good number of small farmers took up hybrid rice cultivation since they felt that its higher yield potential would help them get more rice for their own consumption. The non-availability of seed during planting, high cost of seed, lower market price and low consumer preference acted as factors in the discontinuances of cultivation of hybrid rice by farmers.

The study conclusively revealed that farmer can't use again in sowing of hybrid rice because higher seed costs as compared to HYV rice, moreover they feel distasteful cooking quality, were the major constraints faced by hybrid rice growers, respectively.

Higher cost of seed was found to be a major problem for adoption of hybrid rice technology and hence, the cost of the hybrid seed should be minimised. This can be done by increasing the hybrid seed yields. Hybrid rice fetched low price in comparison with HYV rice, this is mainly due to the reason that though the quality of hybrid rice has improved over the years, still there is a scope to improve the quality of hybrids on par with the HYV varieties to obtain a price similar to HYV rice. This would enable the hybrid rice farmers to get the benefits of this technology by getting fair price for the hybrid rice produce. Being a research scholar I can say from my research experience that hybrid rice is not beneficial than non hybrid only small farmers and some medium farmers use it in food. This is because it gets a low price on sale and cannot be planted with hybrid paddy in canal irrigated areas as it gets ripened early and is not harvested in time.

\section{References}

Chengappa PG, Janaiah A, Srinivasa GMV (2003). Profitability of hybrid rice cultivation

evidence from Karnataka. Econ. Polit. Weekly. 38 (25): 2531-2534.

Dhanavandan, S. (2016). Application of garret ranking technique: Practical approach, International Journal of Library and Information Studies, 6 (3): 135-140.

Nirmala, B. and Suhasini (2013). Farmer's Experience on Hybrid Rice Technology: A Case Study of Jharkhand state of India. African Journal of Agricultural Research, 13 (3): 3973-3975.

Hariprasad, A.S., Virakatmath, B.C and Mohapatra, T. (2014). Hybrid rice in India. FAO/APSA Expert consultation on hybrid rice development in Asia. Assessment of limitations and potential, 2-3, July, 2014, Bangkok.

Peng, S. (2007). Challenges for rice production in China. Rice Today, 6 (4): 38

Singh, H. P., Kujur, M. J. and Kalia, S. (2018). Hybrid Rice: Development, Constraints and Prospects-A review, Bulletin of Environment, Pharmacology and Life Sciences, 7 (12): 01-05.

Tobias, A., Molina, I., Valera, H., Mottaleb, K. and Mohanty, S. (2012). Handbook on rice policy for Asia. Los Baños (Philippines): International Rice Research Institute. $47 \mathrm{p}$.

\section{How to cite this article:}

Sachchidanand Upadhyay, V. K. Singh, Arjun Prasad Verma, Ashwani Kumar Verma and Kumari Asha. 2021. Constraints Analysis in Hybrid Paddy Farming in Eastern Zone of Uttar Pradesh using Garrett Ranking Technique. Int.J.Curr.Microbiol.App.Sci. 10(02): 791-796. doi: https://doi.org/10.20546/ijcmas.2021.1002.094 